\title{
ИССЛЕДОВАНИЕ ДЕСТРУКТИВНОЙ ГИДРОГЕНИЗАЦИЕИ РАБДОПИССИТОВОГО УГЛЯ ЛИПОВЕЦКОГО МЕСТОРОЖДЕНИЯ
}

Рабдописситовые угли, входящие в группу каустобиолитов, известных под общим названием липтобиолиты, отличаются от других углей своей смоляной природой [1]. Количество смоляных телец (палочек) в рабдописситовых углях колеблется от 43 до $71 \%$ (в среднем $53 \%$ ) [ ${ }^{2}$. Самые известные месторождения в СССР - это Липовецкое каменноугольное месторождение Верхне-Суйфунского бассейна на Дальнем Востоке (рабдописситы) и месторождения Ткибули в Западной Грузии (смоляной уголь).

В настоящей работе изучены деструктивной гидрогенизацией рабдописсит Липовецкого месторождения, и исследован механизм деструкции в различных условиях, а также состав полученных продуктов.

В большинстве опытов проводилось не каталитическое гидрирование [3], а гидрирование в водной среде; вода в таком случае является одновременно окисляющим и гидрирующим реагентом $\left[{ }^{4}\right]$, как и при производстве водорода из метана способом конверсии с водой. Состав полученных гидрогенизатов сравнивали со смолой полукоксования, полученной в стандартных условиях по ГОСТу 3168-66.

\section{Экспериментальная часть}

В качестве сырья использовали измельченный рабдописсит со следующими показателями, $\%$ : $W^{a} 1,4 ; A^{c} 20,5 ;\left(\mathrm{CO}_{2}\right)_{\text {карб. }}^{c} 0,3$; элементный состав органического вещества (OB): C 80,$8 ; \mathrm{H} 7,6 ; \mathrm{N}$ следы; O+S 11,6. Выход битумоида: А 1,0 и С 0,6 на ОВ.

Гидрогенизация проводилась в качающемся автоклаве емкостью $2 \Omega$ с электрообогревом. Скорость поднятия температуры 4 град/мuн. Количество загружаемого в автоклав рабдописсита составляло во всех опытах 150 2, соотношение между рабдописситом и циклогексаном (водой, раствором щелочи) - $1: 2$, температура $370^{\circ} \mathrm{C}$, продолжительность опыта 3 . Катализатор (молибдат аммония) наносили на сланец из расчета $1 \%$ молибдена на ОВ.

В автоклаве были проведены:

1. Каталитическая гидрогенизация в среде циклогексана; первоначальное давление водорода 25 aт.

2. Гидрогенизация в среде водного раствора формиата натрия; водород получался в процессе разложения формиата при повышенной температуре. 
3. Конверсия 5\%-ным раствором щелочи: а) без подачи водорода;

б) с первоначальным давлением водорода 25 aT.

4. Конверсия водой.

5. Каталитическая гидрогенизация остатка, полученного в результате конверсии водой в среде циклогексана; первоначальное давление водорода 25 ат.

Разделение продуктов гидрогенизации и полукоксования, а также их анализ были проведены по ранее описанной методике $\left[{ }^{5,6}\right]$.

\section{Обсуждение результатов}

В табл. 1 приведены выход и характеристика деструкции рабдописсита. Выход смолы полукоксования составляет $36 \%$ на ОВ, выход при гидрогенизации в среде циклогексана, а также в растворе формиата приблизительно такой же величины $(34-36 \%)$. Конверсия водой и раствором щелочи под давлением водорода дала более высокий вы-

Выход и характеристика продуктов деструкции рабдописсита $\left(370^{\circ} \mathrm{C}, 3\right.$ ч)

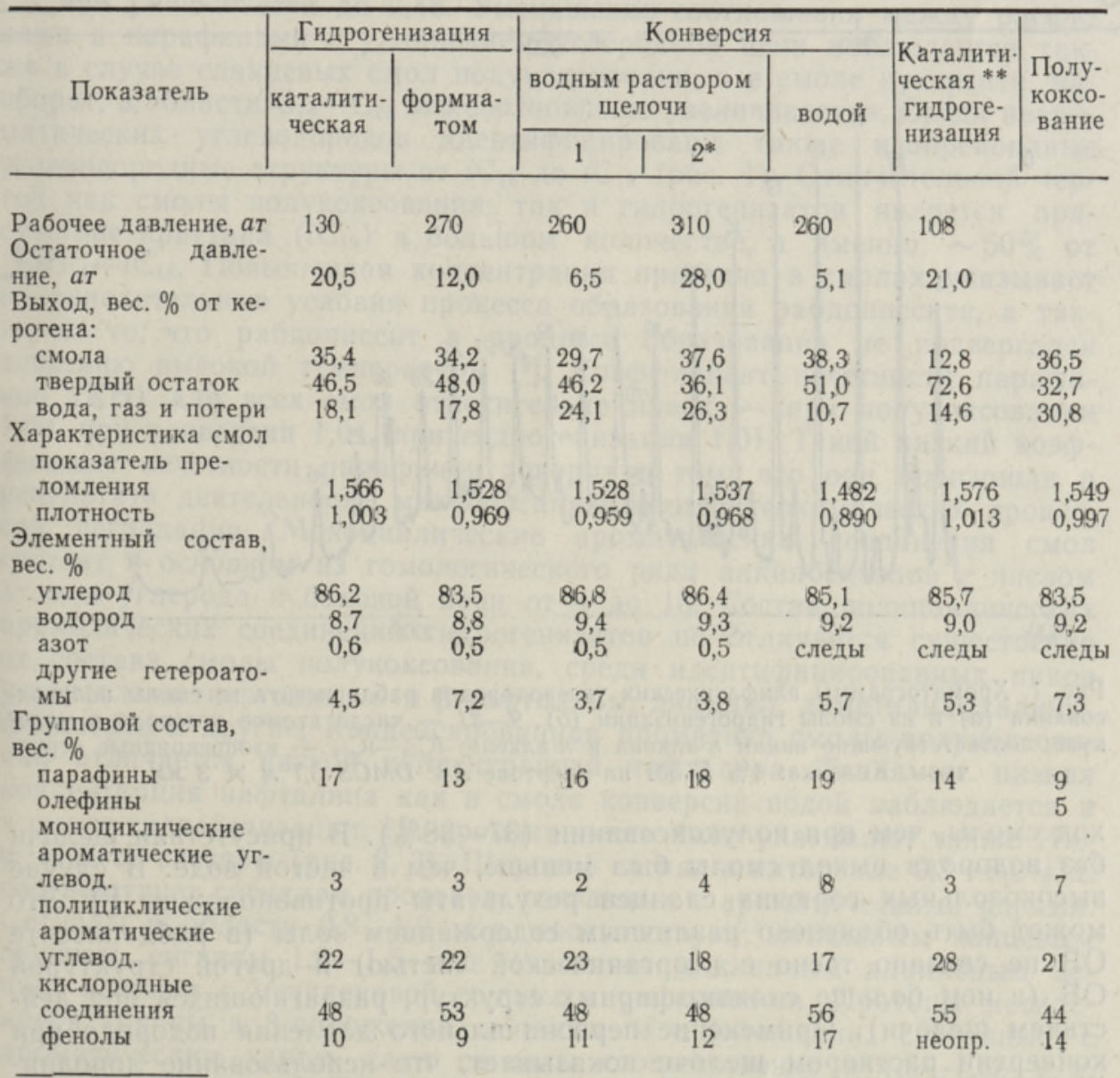

* Под давлением водорода 25 aт.

** Гидрогенизация остатка от опыта конверсии водой. 


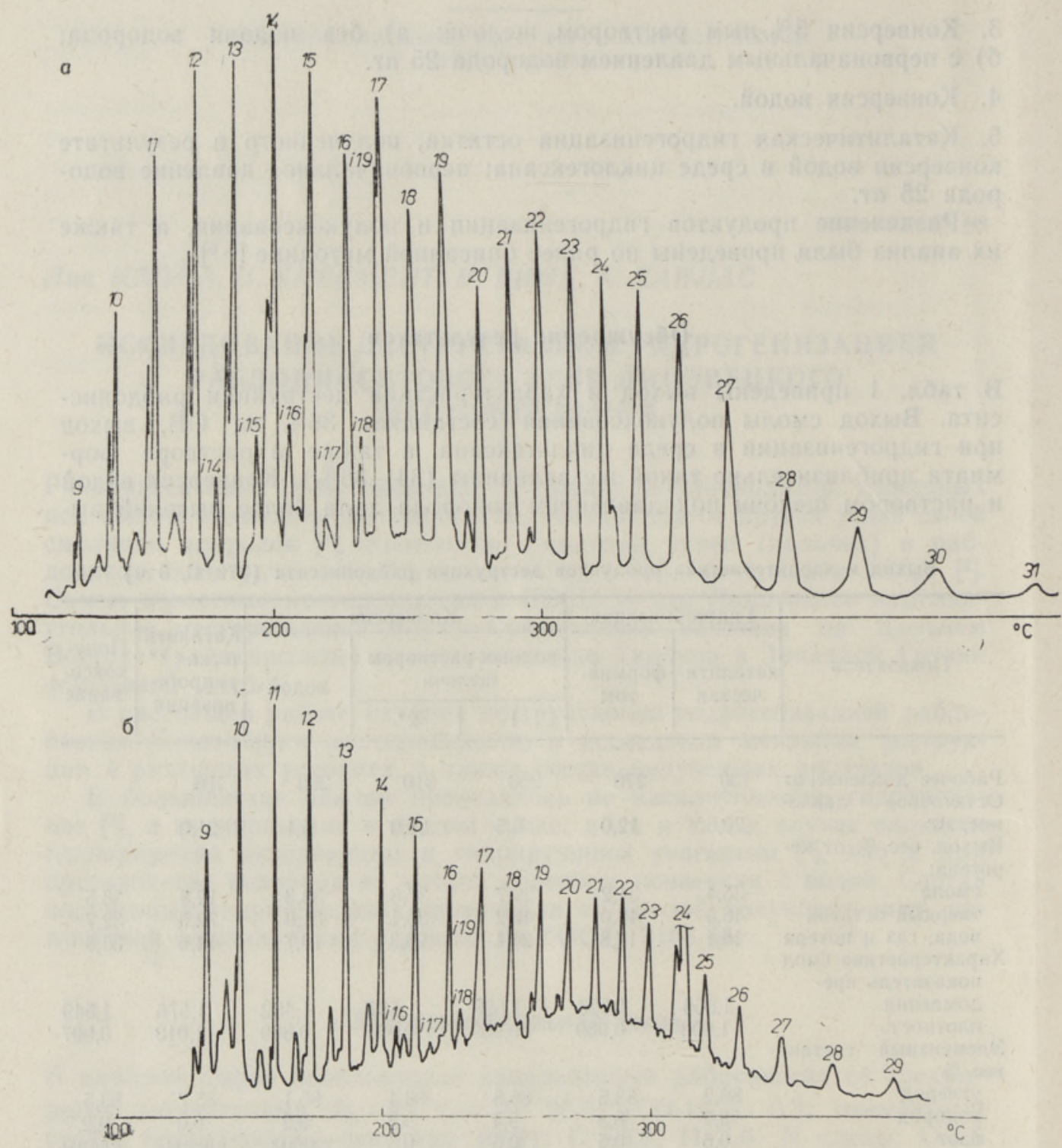

Рис. 1. Хроматограммы алифатических углеводородов рабдописсита из смолы полукоксования $(a)$ и из смолы гидрогенизации (5). $9-31$ - число атомов углерода в молекуле, соответствующие пикам $\mathrm{H}$-алкана и $\mathrm{H}$-алкена; $i \mathrm{C}_{14}-i \mathrm{C}_{19}-$ изопренондные структуры. Колонка: $4 \% E 301$ на инертоне $A W D M C S 3,7 \mu \times 3$ м..

ход смолы, чем при полукоксовании $(37-38 \%)$. В присутствии щелочи без водорода выход смолы был меньше, чем в чистой воде. В случае высокозольных горючих сланцев результаты противоположны [7]. Әто может быть объяснено различным содержанием золы (в рабдописсите $\mathrm{OB}$ не связано тесно с неорганической частью) и другой структурой OB (в нем больше сложноэфирных структур, разлагающихся под действием щелочи). Применение первоначального давления водорода при конверсии раствором щелочи показывает, что использование дополнительного водорода значительно повышает выход смолы. В присутствии водного раствора щелочи образуется много газа, в то время как в чис- 
той воде его образуется чрезвычайно мало, однако в газе конверсии чистой водой в три раза больше метана, в два раза больше этана, пропана и бутана. Состав газа полукоксования характеризуется высоким содержанием (об. \%) метана $(31,8)$ и этана $(10,2)$; другие компоненты присутствуют в меньших концентрациях: пропана - 3,5, н-бутана 1,6 , этилена $-2,8$, пропилена $-2,7$, изобутана $-0,2$, бутилена $-1,3$ и сероводорода $-3,5$.

По показателям плотностей и преломления нет существенной разницы между смолой полукоксования и смолами гидрогенизации, но групповой состав смол разных опытов показывает некоторое различие. Для всех опытов характерно высокое содержание кислородных соединений - около 55-60\%, в том числе фенолов от 10 до $17 \%$. Самый высокий выход фенолов получается при конверсии в чистой воде. Продукты термолиза рабдописситов Ткибульского месторождения, однако, содержат не более $4-5 \%$ фенолов $\left.{ }^{8}\right]$. Смолам гидрогенизации и полукоксования рабдописсита свойственны алифатические углеводороды: прямоцепочечные $\boldsymbol{H}$-парафины от $\mathrm{C}_{9}$ до $\mathrm{C}_{31}$. В смоле полукоксования присутствуют и алифатические олефины. Соотношение между олефинами и парафинами в смоле полукоксования рабдописсита в пределе $\mathrm{C}_{9}-\mathrm{C}_{13}$ составляет 0,58 , с удлинением цепи углеводородов от $\mathrm{C}_{14}$ до $\mathrm{C}_{19}$ оно уменьшается до 0,48 . Уменьшение соотношения между олефинами и парафинами с удлинением углеродной цепи наблюдается также в случае сланцевых смол полукоксования, а в смоле кукерсита, наоборот, в области $\mathrm{C}_{14}-\mathrm{C}_{19}$ это соотношение увеличивается. Среди неароматических углеводородов идентифицированы также изопреноидные углеводородные структуры от $i \mathrm{C}_{14}$ до $i \mathrm{C}_{19}$ (рис. 1$)$. Отличительной чертой как смолы полукоксования, так и гидрогенизатов является присутствие пристана $\left(i \mathrm{C}_{19}\right)$ в большом количестве, а именно $\sim 50 \%$ от $\sum i \mathrm{C}_{14}-i \mathrm{C}_{18}$. Повышенная концентрация пристана в смолах указывает на окислительные условия процесса образования рабдописсита, а также на то, что рабдописсит в процессе образования не подвергался действию высокой температуры []. Коэффициент нечетности парафинов $(\mathrm{KH})$ для всех смол относительно низок - при полукоксовании 1,09 , при конверсии 1,04, при гидрогенизации 1,01. Такой низкий коэффициент нечетности парафинов говорит о том, что они произошли в результате деятельности микроорганизмов или геохимических процессов деградации. Моноциклические ароматические соединения смол состоят в основном из гомологического ряда алкилбензолов с числом атомов углерода в боковой цепи от 4 до 16. Состав полициклических ароматических соединений гидрогенизатов не отличается существенно от состава смолы полукоксования, среди идентифицированных пиков установлены нафталин, $\alpha$ - и $\beta$-нафталины, дифенил, диметилнафталины, фенантрен и другие. Конденсированная ароматика смолы полукоксования отличается низкой концентрацией нафталина. Такая же низкая концентрация нафталина как в смоле конверсии водой наблюдается и в смоле гидрогенизации. На ароматичность смол указывают также ИКи ${ }^{1} \mathrm{H}$ ЯМР-спектры (рис. 2, 3). Широкий сигнал в интервале $6,3-8,0$ м. д. соответствует сигналам протонов, связанных с ароматическими ядрами. Сигналы в области $0,8-1,0$ м.д. соответствуют метильным концевым группам, сигналы $1,2-1,5$ м. д. относятся к длинным алкильным цепям, начиная с метиленовой группы в $\gamma$-положении. Протоны метиленовой группы в $\beta$-положении, а также в $\alpha$-положении, связанные с ароматическим ядром, дают сигналы соответственно в 1,5-1,65 м.д. и $1,88-2,37$ м. д. В ИК-спектрах имеется в наличии комплекс полос поглощения, свойственный ароматическим соединениям: при 750, 760, 

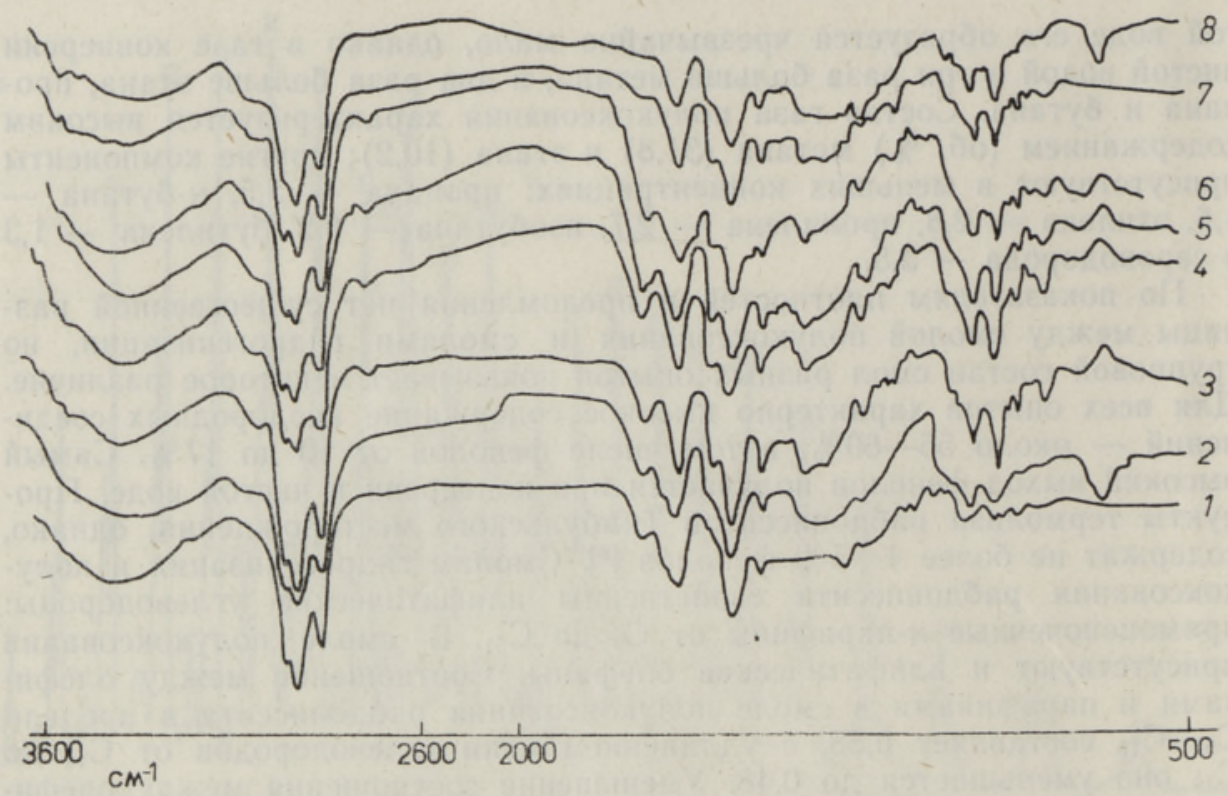

Рис. 2. ИК-спектры смол гидрогенизации и полукоксования рабдописсита. 1 - полукоксование кукерсита, 2 - полукоксование рабдописсита, 3 - гидрогенизация в среде водного раствора формиата, 4 - конверсия $5 \%$-ным раствором щелочи, 5 - конверсия $5 \%$-ным раствором щелочи, с начальным давлением водорода $25 a t, 6-$ конверсия водой, 7 - каталитическая гидрогенизация в среде циклогексана, 8 - гидрогенизация остатка от конверсии водой в среде циклогексана.

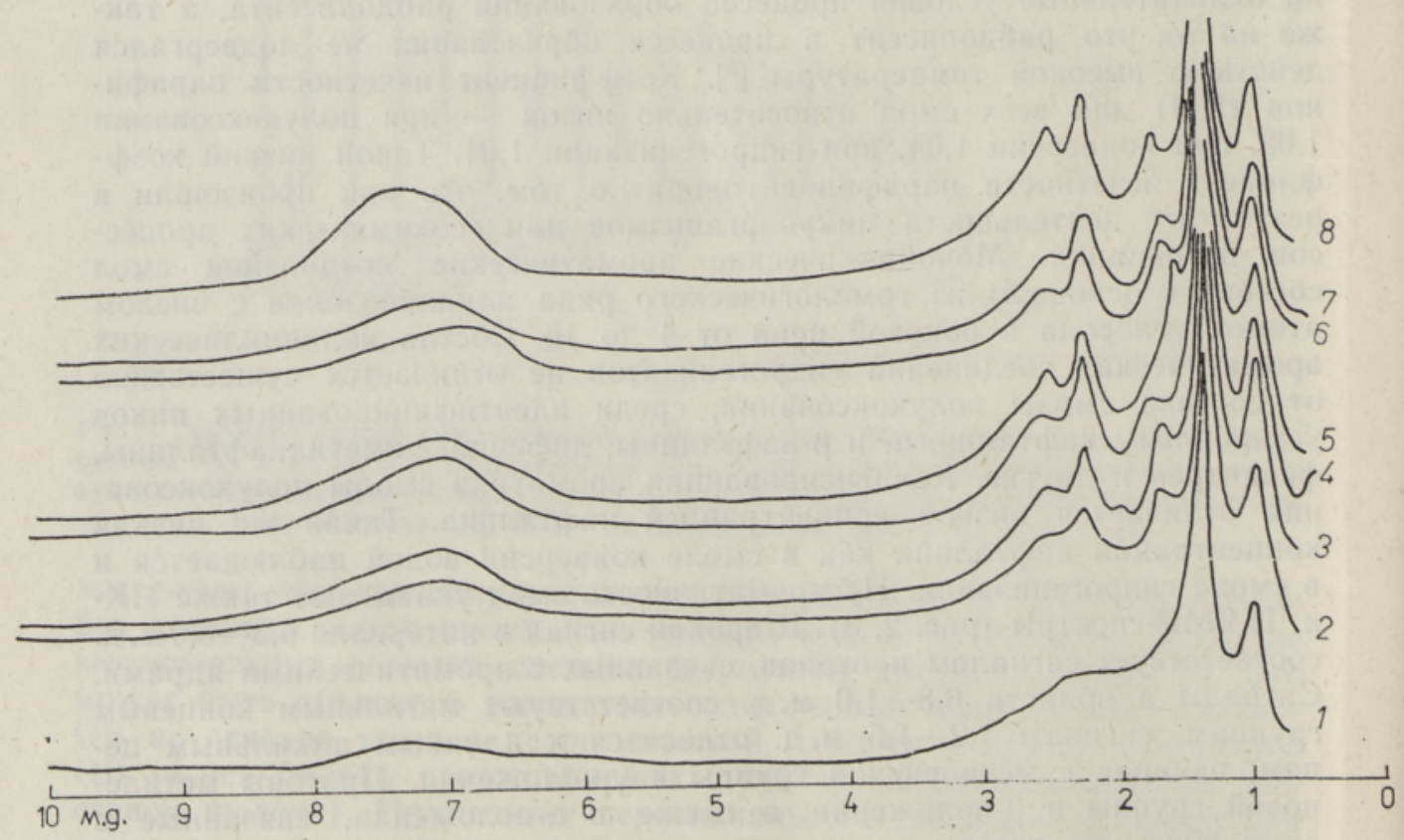

Рис. 3. Спектры протонного ЯМР. Спектры сняты из $10 \%$-ных растворов $\mathrm{CCl}_{4}$ при частоте до $60 \mathrm{M} Г$ ц. Обозначения см. на рис. 2. 
$840,900,1020,1080,1600,3039$ см$^{-1}$. Для сравнения на рис. 2 и 3 приведены ИК- и ${ }^{1} \mathrm{H}$ ЯМР-спектры смолы полукоксования кукерсита. Во фракциях кислородсодержащих соединений присутствуют $H$-алканоны от $\mathrm{C}_{9}$ до $\mathrm{C}_{19}$, в основном типа метилкетонов, Из фенолов идентифицированы одноосновные (фенол, 0 -, $M$-, $n$-крезолы), а также в небольшом количестве двухосновные (по-видимому, типа резорцина) и двухатомные (нафтол) фенолы. В реакционных водах конверсии и гидрогенизации найдены лишь монокарбоновые кислоты от $\mathrm{C}_{5}$ до $\mathrm{C}_{9}$ (определялись хроматографически в виде метиловых эфиров). В реакционной воде конверсии кроме кислот присутствуют также двухосновные фенолы типа резорцина.

На основе проведенного исследования можно сделать следующие выводы. Несмотря на высокое содержание водорода в ОВ, выход смолы при термической деструкции относительно низок и не увеличивается также при гидрогенизации. Это указывает на большое количество конденсированных циклов в ОВ. В смолах много кислорода, который находится, вероятно, в структуре циклических эфиров. По содержанию ароматических и алифатических структур смолы более близки к сланцевым смолам, чем к каменноугольным, при деструкции алифатические структуры переходили в летучие продукты.

\section{ЛИ Т Е Р А Т У Р А}

1. Жем чужников Ю. А. Введение в петрографию углей. - Тр. ОПТИ НКТП СССР. M.-Л., 1934.

2. Н о в иц к ий Н. В., М а р тын о в а М. Н. Характеристика углей Липовецкого месторождения. - Хим. тв. топлива, 1967 , № 6, с. $52-57$.

3. К ричко А. А. Проблемы комплексного использования угля. - Химия тв. топлива, 1977 , № 6, с. 3-10.

4. Ф ридм ан Г. Е., Переслени Н. М. Термическое разложение горючих сланцев в присутствии вод давлением. - Тр. ИГИ, 1962 , т. 17 , с. $60-75$.

5. Klesment, I. Application of chromatographic methods in biogeochemical investigations. - J. Chromatogr., 1974, v. 91, p. 705-713.

6. Н аппа Л., К лесмент И., В инк Н., Кайлас К. Изучение органического вещества горючего сланца месторождения «Мандра» низкотемпературной деструктивной гидрогенизацией. - Изв. АН ЭССР. Хим., 1979, т. 28, № 3, c. $191-197$.

7. Наппа Л., Клесмент И., Винк Н., Кайлас К. Деструктивная гидрогенизация диктионемовых сланцев. - Изв. АН ЭССР. Хим., 1980, т. 29, № 2, c. $84-91$.

8. Ци и к а и ш в ли П. Д. Исследование в области химни и технологии рабдописснтовых углей. Тбилиси, 1967.

9. B r a y, E. E., Eva n S E. D. Distribution of $n$-paraffins as a clue to recognition of source beds. - Geochim. Cosmochim. Acta, 1961, v. 22, N 1, p. 2-9.

Ннститут химии
Академии наук Эстонской ССР

Поступила в редакцию 6/II 1980

Lia NAPPA, I. KLESMENT, N. VINK, K. KAILAS

\section{LIPOVETSKI LEIUKOHA RABDOPISSIITSE SOE DESTRUKTIIVNE HODROGEENIMINE}

Artiklis on esitatud katseandmed rabdopissiitse söe hüdrogeenimise, veega konversiooni ja poolkoksistamise kohta. Orgaanilise aine suurest vesinikusisaldusest hoolimata on rabdopissiidi taandaval destruktsioonil saadava õli saagis madal. See viitab kondenseerunud tsüklite esinemisele orgaanilises aines. Aromaatsete ja alifaatsete ühendite sisalduse poolest sarnaneb saadud õli rohkem põlevkiviõli kui kivisöetôrvaga. 
Lia NAPPA, I. KLESMENT, N. VINK, K. KAILAS

\section{INVESTIGATION OF DESTRUCTIVE HYDROGENATION OF LIPOVETSK RABDOPISSITE COAL}

The results of hydrogenation, conversion with water and semicoking are presented. In spite of a high hydrogen content in organic matter, the yields of liquefication products are low. This refers to the presence of condensed cycles in the structure of organic matter. The oils obtained by semicoking and hydrogenation are more similar to shale oils than to the coal semicoking tars. 